\title{
Anomalous Variations of lonosphere Associated with the Strong Earthquake at Pakistan-Iran Border at a Low Latitude Station Agra, India
}

\author{
Devbrat PUNDHIR ${ }^{1,3}$, Birbal SINGH ${ }^{1}$, O.P. $\mathrm{SINGH}^{2}$, \\ and Saral K. GUPTA ${ }^{2}$ \\ ${ }^{1}$ Department of Electronics and Communication Engineering, \\ Raja Balwant Singh Engineering Technical Campus, Bichpuri, Agra, India \\ ${ }^{2}$ Department of Physics, Raja Balwant Singh Engineering Technical Campus, \\ Bichpuri, Agra, India \\ ${ }^{3}$ Department of Physics, Banasthali University, Rajasthan, India \\ e-mail: devbratpundhir@gmail.com (corresponding author)
}

\begin{abstract}
In this paper, we analyze the TEC data for April 2013 observed at Agra station, India (geogr. lat. $27.2^{\circ} \mathrm{N}$, long. $78^{\circ} \mathrm{E}$ ) to examine the effect of earthquake of magnitude $M=7.8$ which occurred on 16 April 2013 at Pakistan-Iran border region. We process the TEC data using the $\sigma$ statistical criterion to find out anomalous variation in TEC data. We also study the VLF propagation signal from NPM, Hawaii $\left(21.42^{\circ} \mathrm{N}\right.$, $158^{\circ} \mathrm{W}$ ), which is monitored at the same station (Agra station) in the light of this earthquake as well as solar flares. The nighttime fluctuation method is used to analyze the VLF data for the period of \pm 5 days from the day of earthquake (11-21 April 2013). The anomalous enhancements and depletions are found in TEC data on 1-9 days before the occurrence of event.
\end{abstract}

Key words: GPS-TEC, VLF, precursors. 


\section{INTRODUCTION}

Various techniques for possible earthquake prediction have been found and used, in which the one based on ionospheric measurements has found widespread attention and importance. Due to availability of global positioning satellites (GPS), numerous measurements of lower and upper ionosphere have been taken and very interesting results have been reported (Singh and Singh 2004, Liu et al. 2006, Molchanov and Hayakawa 2008, Le et al. 2011, Maurya et al. 2013, Pundhir et al. 2014). For example, Liu et al. (2001) have carried out both the $f_{o} \mathrm{~F} 2$ measurements using Chug-Li ground based ionosonde and GPS based total electron content (GPS-TEC) measurements corresponding to Chi-Chi earthquake $(M=7.7)$ in Taiwan and found 1-4 days of ionospheric precursors. Liu et al. (2004a) have examined the effect of 20 earthquakes $(M \geq 6.0)$ occurred in Taiwan area between 1999 to 2002 on the variation of TEC and found 1-5 day precursory period. Pulinets and Boyarchuk (2004) presented an excellent review on ionospheric precursors of earthquakes. Statistical studies for pre-earthquake ionospheric anomalies have been carried out by Liu et al. $(2006,2009)$. Recent studies based on consideration of large number of earthquakes over extended period of time and their influence on the variation of GPS-TEC have been carried out by Liu et al. (2009) and Akhoondzadeh et al. (2012). Akhoonzadeh (2012) has studied the GPS-TEC variation associated with the powerful Tohoku earthquake of 11 March 2011, and reported convincing precursors on 1-3 days prior to occurrence of earthquake. More recently, Pundhir et al. (2014) have studied the effect of multiple earthquakes on GPS-TEC data and found the precursors on 1-9 days before the occurrence of main shock.

Lower ionosphere studies have also been done by Hayakawa et al. (2010a) who presented statistical study of nighttime VLF signal associated with the earthquake. They have found that a significant statistical correlation between VLF/LF propagation anomaly, including a decrease in nighttime average amplitude (trend) and an enhancement in nighttime fluctuation for EQs with larger magnitude $(M \geq 6)$. Further, Hayakawa et al. (2010b) have also shown the statistical results on long term data of 7 years. It is found that the propagation anomaly exceeding $2 \sigma$ (standard deviation) criterion indicating the presence of ionospheric perturbation is significantly correlated with earthquakes with shallow depth $(<40 \mathrm{~km})$. Ray et al. (2011) have found, by analyzing individual cases (with magnitudes $>5$ ) as well as statistical analysis (of all the events with effective magnitudes greater than 3.5), that nighttime fluctuation of the signal amplitude has the highest probability to be beyond the $2 \sigma$ level about three days prior to seismic events. Thus, the night time fluctuation could be considered as a precursor to enhanced seismic activities. 
Ono et al. (2012) show the results of VLF signal nighttime study of two huge earthquakes in Japan using the principle component analysis (PCA). They suggested that trend as the average nighttime amplitude is significantly decreased, with almost simultaneous significant enhancement in the nighttime fluctuation as the night-time integration of negative fluctuation from the average during the earthquakes. Recently, Hayakawa et al. (2013) have shown the nighttime analysis of multi VLF signals and discussed the effect of earthquakes and magnetic storms on VLF/LF anomaly. They have also compared the temporal properties of ionospheric perturbations for this EQ with those of a huge number of inland EQs and compared the corresponding spatial scale with the former result of the same oceanic 2004 Sumatra EQ with nearly the same magnitude.

In India, the studies of ionospheric precursors have also been done at Agra (Chauhan et al. 2012, Pundhir et al. 2014), Guwahati (Devi et al. 2012), Kolkata (DasGupta et al. 2006), Varanasi (Singh et al. 2012), Delhi (Dabas et al. 2007), Surat (Karia and Pathak 2011), Allahabad (Maurya et al. 2013).

A major devastating earthquake of magnitude $M=7.8$ occurred at Pakistan-Iran border region on 16 April 2013 causing widespread loss of life and property not only in adjoining region of Iran-Pakistan but also in surrounding countries like Afghanistan, India, etc. In the present paper, we examine the effect of this earthquake on TEC data observed at Agra for April 2013 and show that the anomalous variation in the data occurred in the form of enhancements and depletions. We have also examined the VLF propagation signals from NPM, Hawaii, which have been observed at Agra station in the light of 16 April 2013 large earthquake of magnitude $M=7.8$ and we use statistical techniques for the refining of our results.

\section{EXPERIMENTAL SETUP}

\subsection{TEC setup}

The experimental setup used for TEC measurements at Agra station is similar to that used by our group earlier (Singh et al. 2010). The equipments which are related to experimental setup have been imported from Silicon Valley, USA, and consist of an $\mathrm{L}_{1} / \mathrm{L}_{2}$ GPS antenna (Novatel's Model GPS 702), a GPS receiver (Novatel's Euro Pak 3-M), connecting cables and relevant software (novatel.com). The GPS receiver and antenna are placed in the Seismo-Electromagnetic and Space Research Laboratory (SESRL) in the Faculty of Engineering building at Bichpuri Campus of our college and round the clock observations are taken. Bichpuri is located in rural area about $12 \mathrm{~km}$ west of Agra city where local electrical and electromagnetic disturbances are extremely low. 


\subsection{VLF setup}

Monitoring of phase and amplitude of VLF transmitter signals has also been in progress at Bichpuri campus of R.B.S. College, Agra, since 1 August 2002. Initially, we employed AbsPAL (Absolute Phase and Amplitude Logger) system (Dowden et al. 1994) but later replaced it by modified software based system (SoftPAL) on 1 April 2010. We monitor the phase and amplitude of three different signals of frequencies $19.8 \mathrm{kHz}$ (NWC, Australia), $21.4 \mathrm{kHz}$ (NPM, Hawaii), and $24 \mathrm{kHz}$ (NAA, Cutler, Maine). The sampling rate used is $60 \mathrm{~s}$.

\section{METHOD OF DATA ANALYSIS}

We use the well-developed statistical $\sigma$ criterion to analyze the TEC data for April 2013 to find the anomalous variation in data (Chauhan et al. 2009, Singh et al. 2010). We calculate the mean and standard deviation corresponding to each of 15 day interval occurring before and after the earthquake because it is more useful with respect to others. Finally, we find the mean $\pm \sigma$ to calculate dTEC variation.

The NPM, Hawaii, USA $\left(21.42^{\circ} \mathrm{N}, 158.154^{\circ} \mathrm{W}\right)$, VLF transmitter amplitude and phase were recorded by SoftPAL receiver installed at a quiet location Bichpuri, Agra, India $\left(27.2^{\circ} \mathrm{N}, 78^{\circ} \mathrm{E}\right)$. In the present study, only amplitude signal of NPM transmitter has been used. We use only \pm 5 days VLF data from the period of 11-21 April 2013 for our analysis because of the non-availability of accurate data at our center for other days. We use nighttime fluctuation (NF) method to investigate the seismo-ionospheric effect of this earthquake as used and well explained by earlier workers (Hayakawa et al. 2010b; 2011, Kasahara et al. 2008) and it is most suitable to examine the seismic effect. We use the two hours local nighttime data of 14:00-16:00 UT and estimated the difference $d A(t)$ for a particular day as $d A(t)=(A(t)-<A(t)>)$, where $A(t)$ is the VLF amplitude at time $t$ on that particular day and $\langle A(t)\rangle$ is the average value at the same time for 11 days from 11-21 April 2013. We have estimated two parameters as defined by Kasahara et al. (2008) and Hayakawa et al. (2010b) using difference $d A(t)$. First is trend $T$ difference of the VLF amplitude at time $t$ and average of the VLF amplitude at same time $t$, and second is dispersion $D$, standard deviation $S D$ of the nighttime amplitude difference $d A(t)$ for each day.

\section{RESULTS AND DISCUSSION}

\subsection{TEC}

Figure 1 shows a map of Asia in which the epicenter of the earthquake ( $M=$ 7.8, shown by stars) occurred at Pakistan-Iran border region on 16 April 2013 and the observing station Agra, India (by solid circle) are shown. The 


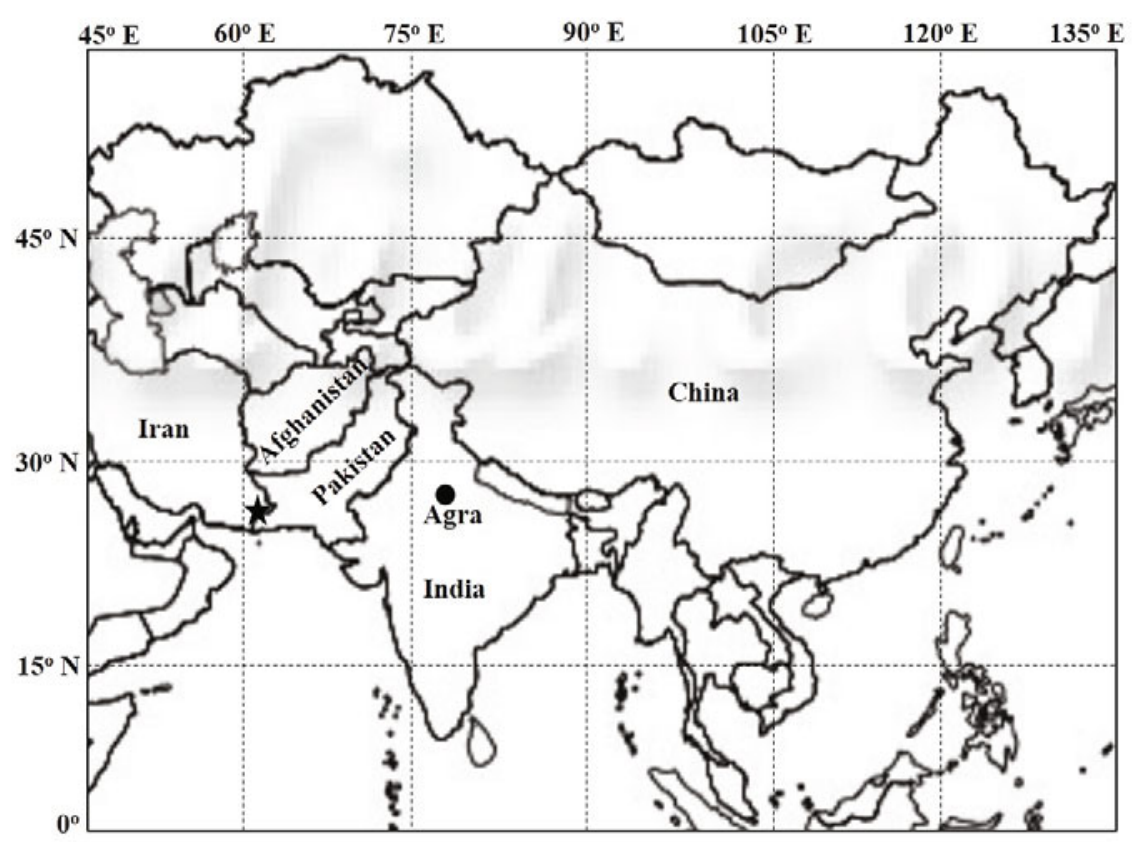

Fig. 1. The map of Asia indicating the epicenter of earthquake (by star). The solid circle shows the location of TEC observing station Agra in India.

earthquake data are taken from the United State Geological Survey (USGS) through website: www.earthquake.usgs.gov.in.

Now, we study the diurnal variation in GPS-TEC observed at Agra for the period under consideration, as shown in Fig. 2a. The data show observed TEC in blue colour, and lower (mean $-\sigma$ ) and upper (mean $+\sigma$ ) bounds in green and red colours, respectively. The large solid star on 16 April indicates the occurrence day of large earthquake $(M=7.8)$. The enhancements and depletions beyond the mean $\pm \sigma$ are shown in Fig. 2b. Figures $2 \mathrm{c}$ and $\mathrm{d}$ show the variation of $D s t$ index $(D s t)$ and $\Sigma K p$ for the same period. These are magnetic storm indices for which the data are taken from the website of NASA: http://omniweb.gsfc.nasa.gov/form/dx1.html. The largest enhancement beyond the upper bound (mean $+\sigma$ ) occurred on 9 April, whereas relatively smaller enhancements occurred on 8-16 and 24-29 April. A significant depletion in data on 1 April may also be attributed to this earthquake. There are some minor enhancements and depletions in the data on other days of the month also but they are insignificant as compared to those mentioned above. Now, we need to explain the anomalous enhancements and depletions in the TEC data in the light of magnetic storm variation and the effect of this earthquake. The variations of $D s t$ and $\Sigma K p$ show almost quiet magnetic con- 

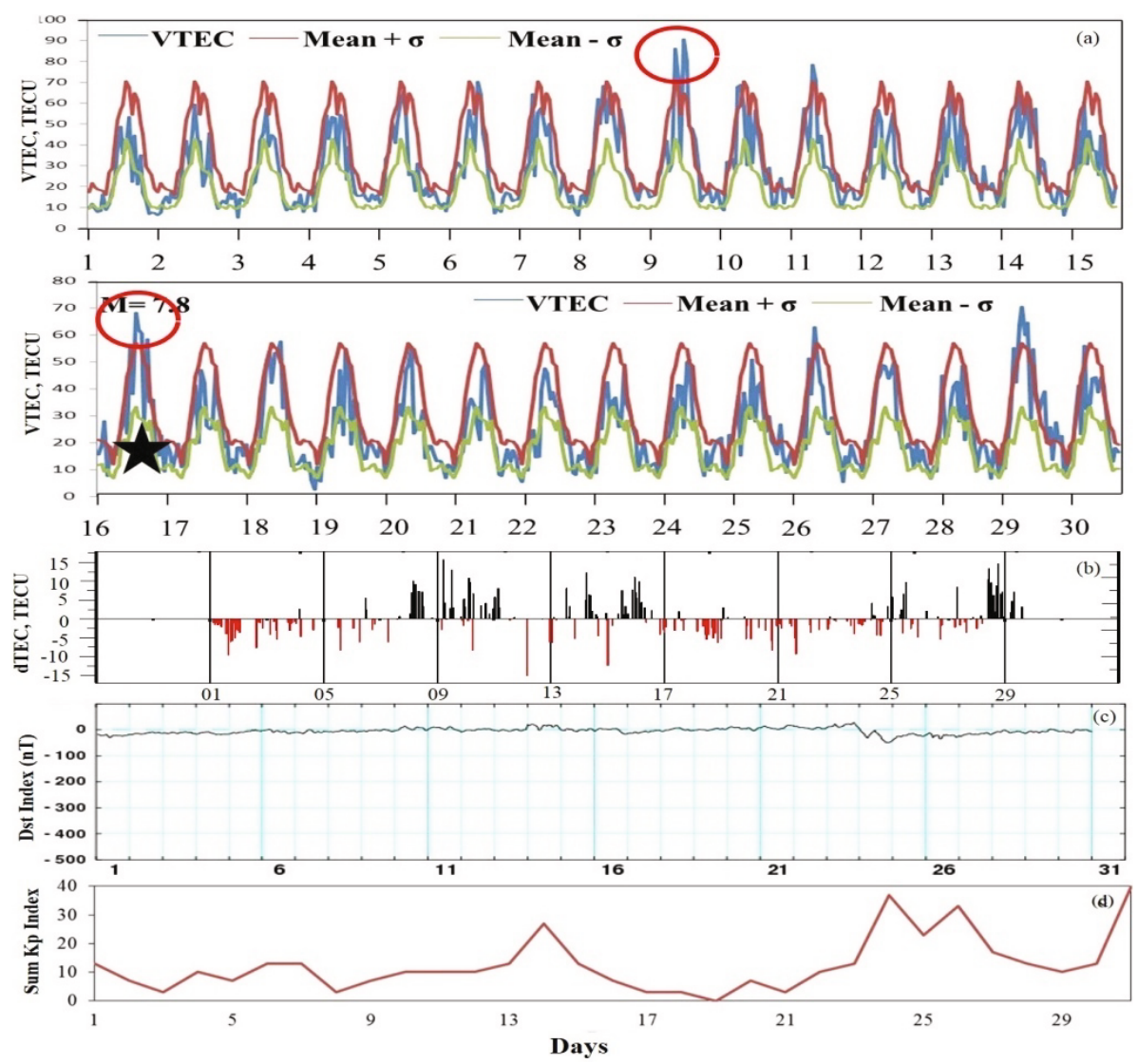

Fig. 2: (a) The variation of GPS-TEC from 1 April to 1 May 2013 (blue), mean $+\sigma$ (red), and mean $-\sigma$ (green). The star shows the occurrence day of earthquake $(M=$ 7.8) at Pakistan-Iran border region; (b) the enhancements and depletions from the mean $\pm \sigma$ by black and red bars, respectively; (c) and (d) the variation of Dst index and $\Sigma K p$, respectively.

ditions in April, except an isolated small magnetic storm on 24 April (Dst $=$ $-49 \mathrm{nT}, \Sigma K p=37)$. Hence, it is possible that the electric fields due to these magnetic storms penetrated the low latitude ionosphere and gave rise to enhancements in TEC on 29 April. However, we need to examine the anomalous period which is not affected by magnetic storm in the light of earthquake. This earthquake may be attributed to be responsible for the anomalous variation of TEC on 9 April and those occurring between 6 April and the day of earthquake (16 April). The data show a precursory period of 1-9 days in which TEC anomalies have occurred. 


\subsection{VLF amplitude perturbations}

The comparison of the average amplitude of 11 days and the VLF amplitude from 11 to 16 April 2013 is shown in Fig. 3. It can be clearly seen from the figure that the enhancements in the amplitude have been found on 1114 April 2013, i.e., 2-5 days before the occurrence of earthquake. The enhancements in VLF amplitude were most likely due to additional ionization (basically increase in electron density). The depletions in amplitude have also been found from 15 to 16 April 2013, which may the effect of this earthquake. The decrease in amplitude of VLF signal is due to seismic effects (Hayakawa et al. 2010b).

We have looked for four possible mechanisms for electron density enhancement in the D region and hence the enhancement in NPM VLF amplitude. These are as follows: (a) solar flares (Zigman et al. 2007), (b) geomagnetic storm (Peter et al. 2006), (c) lower ionospheric heating due to lightning discharges causing VLF events (Inan et al. 1996), and (d) seismic origin due to 16 April 2013 earthquake. We checked and found some flares (C1.5 and C3.6 classes) on 16 April and 21 April of our period of consideration but the effect of these flares cannot be observed because we have used only nighttime VLF data. The solar flare data are taken from the website www.spaceweather.com. We have seen the enhancements and reductions in VLF amplitude on 11-14 and 15-16 April beyond the 11 days mean, respectively. The geomagnetic conditions during the period of observation (1121 April 2013) were almost quiet; it can be seen in Figs. 2b and c and more details about the geomagnetic conditions, as discussed in Section 5. Thus,

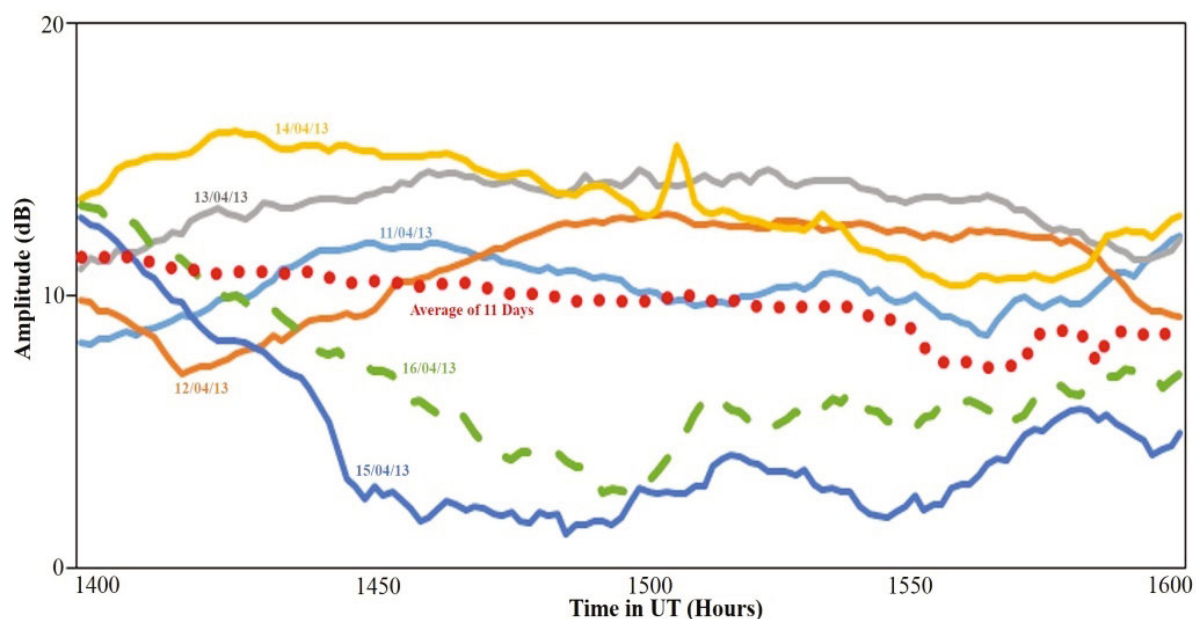

Fig. 3. A plot of VLF amplitude from 11 to April 2013; dotted line shows the average of 11 days and dashed green line shows the amplitude variation on the day of earthquake (16 April 2013). 
there was no significant geomagnetic activity to affect the lower ionosphere during period of the VLF data presented here. So we can say that VLF data was not affected by the geomagnetic storms during the period of observation and another reason of enhancement may be the $E \times B$ drift mechanism which can modify the lower ionosphere. It has been discussed in detail in Section 5. So we can conclude here that the perturbations in VLF amplitude, may be due to this large earthquake $(M=7.8)$.

\subsubsection{Nighttime fluctuation method}

Figure 4 shows trend and dispersion of the VLF amplitude data. The horizontal lines in each panel show the standard deviation $(\sigma)$. Here, we have used $\sigma$ criterion. The trend and dispersion have been satisfied by this criterion. Generally, the VLF anomalies take place 5-7 days before the occurrence of earthquake (Hayakawa et al. 2010b) but in our case the anomaly is 1-3 days before the earthquake. We have also compared our results with the previously reported results such as Hayakawa et al. (2010b) who studied 7 years long period of data and applied the nighttime fluctuation analysis and concluded that trend shows a significant decrease before the earthquake. The study of this earthquake $(M=7.8)$ at Pakistan-Iran border region shows similar results for trend. The VLF propagation anomalies in trend, dispersion and fluctuation have been explained in terms of acoustic gravity waves which is discussed in detail in Section 5.

The nighttime fluctuation analysis results indicated that acoustic gravity waves and static electric field are two possible mechanism which are associ-

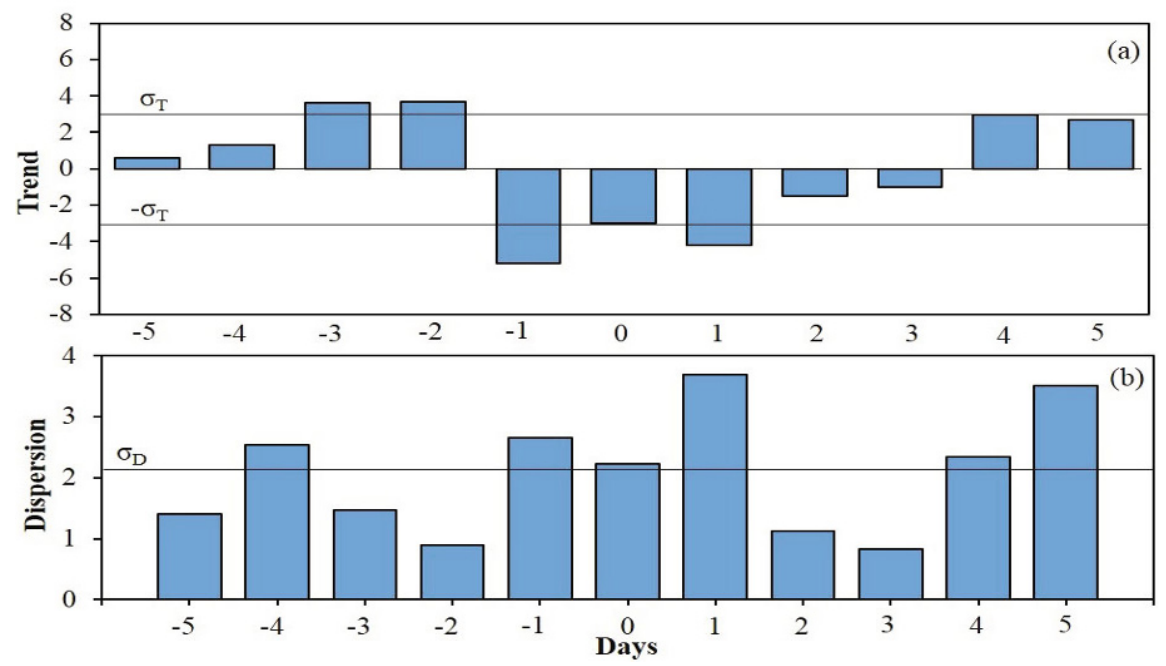

Fig. 4. Nighttime fluctuation analysis for: (a) trend, and (b) dispersion. The horizontal lines in each panel show $\sigma$ criterion to define the anomalous day. 
ated with this large earthquake $(M=7.8)$ because of its higher magnitude and lower depth. It may also affect the upper ionosphere as we have discussed in Section 5. The effect of large earthquakes has also been examined by other workers (Zhao et al. 2008, Liu et al. 2009, Sarkar and Gwal 2010) in a similar way.

\section{DISCUSSION}

The question is how these anomalous variations in data have been found at low latitudes. So we need to explain the exact reason of anomalous variation using the coupling mechanisms between the lithosphere, atmosphere, and ionosphere, involving atmospheric gravity waves, and the vertical electric fields generated during the earthquake preparation periods, as suggested by earlier workers (Hayakawa and Fujinawa 1994, Hayakawa 1999, Hayakawa and Molchanov 2002, Pulinets 2004, 2009). In the results of TEC presented above, we have emphasized the generation of positive anomalies (enhancements in TEC) in the light of large earthquake of 16 April 2013. This result is supported by earlier workers (Liu et al. 2004b, Dabas et al. 2007, Devi et al. 2012). However, recently some workers have shown the significance of negative and positive TEC anomalies also (Liu et al. 2009, 2010, Pulinets 2012).

Adopting the mechanism of lithosphere-ionosphere coupling, possible explanations have been presented by many workers in terms of $E \times B$ drift where the electric field $(E)$ triggered by an earthquake preparatory process penetrates the ionosphere, in the presence of local magnetic field $(B)$. More details of this mechanism can be found in the recent monograph (Pulinets and Davidenko 2014). Pulinets (2004) suggested that radon emissions emanating from earthquake region ionize the near-earth atmosphere over the seismic zone and cause formation of quasi-neutral clusters at a first stage of seismo-ionospheric coupling. It is also found that the concentration of greenhouse gases is enhanced over the earthquake preparation zone (Khilyuk et al. 2002, Inan et al. 2008) which effects in two important forms. Firstly, the creation of instabilities which are responsible to stimulate acoustic gravity waves generation and second the air motion destroys these ion clusters as a result of which the near ground layer of atmosphere becomes rich in ion within a short time. The charge separation process then leads to generation of anomalously strong vertical electric field $\left(\approx \mathrm{KVm}^{-1}\right)$ in comparison with the fair weather electric field $\left(\approx 100 \mathrm{Vm}^{-1}\right)$. Pulinets $(2009)$ provides an explanation of the existence of a vertical atmospheric electric field and coupling between the ground and the ionosphere using the concept of Global Electric Circuit (GEC). In brief, GEC is the system of quasi-stationary electric current between ground and ionosphere driven by global thunderstorm 
activity and works in transmitting the information from the ground surface up to the ionosphere by changing its electric properties due to natural ionization and ion-induced nucleation changing the conductivity of atmosphere (Pulinets and Davidenko 2014).

At low latitudes, such as that of Agra, equatorial ionospheric anomaly (EIA) controls the ionospheric phenomena strongly and it is possible that according to the mechanism suggested above, the upward electric field penetrates the ionosphere eastward and - in the presence of local magnetic field causes an enhancement in GPS-TEC. The results of VLF propagation signal show the proof of lower ionospheric perturbations associated with this earthquake. We have explained the results of lower and upper ionosphere in the light of two mechanisms, $E \times B$ drift and acoustic gravity waves.

In this paper we have tried to correlate the upper and lower ionosphere using the valid mechanisms and supported results of earlier workers. The parallel study of lower and upper ionosphere may be very useful for examination of seismic effects and a powerful tool of earthquake monitoring and forecasting. We have discussed all the aspects which are related to anomalous variations of ionosphere.

Acknowledgement. The authors are thankful to Department of Science and Technology, Government of India, New Delhi, and Ministry of Earth Sciences, Government of India, New Delhi, for financial support.

\section{References}

Akhoondzadeh, M. (2012), Anomalous TEC variations associated with the powerful Tohoku earthquake of 11 March 2011, Nat. Hazards Earth Syst. Sci. 12, 5, 1453-1462, DOI: 10.5194/nhess-12-1453-2012.

Chauhan, V., O.P. Singh, V. Kushwah, V. Singh, and B. Singh (2009), Ultra-lowfrequency (ULF) and total electron content (TEC) anomalies observed at Agra and their association with regional earthquakes, J. Geodyn. 48, 2, 6874, DOI: 10.1016/j.jog.2009.06.002.

Chauhan, V., O.P. Singh, U. Pandey, B. Singh, B.R. Arrora, G. Rawat, B.M. Pathan, A.K. Sinha, A.K. Sharma, and A.V. Patil (2012), A search for precursors of earthquakes from multi-station ULF observations and TEC measurements in India, Ind. J. Radio Space Phys. 41, 543-556.

Dabas, R.S., R.M. Das, K. Sharma, and K.G.M. Pillai (2007), Ionospheric precursors observed over low latitudes during some of the recent major earthquakes, J. Atmos. Sol.-Terr. Phys. 69, 15, 1813-1824, DOI: 10.1016/j.jastp. 2007.09.005. 
DasGupta, A., A. Das, D. Hui, K.K. Bandyopadhyay, and M.R. Sivaraman (2006), Ionospheric perturbations observed by the GPS following the December 26th, 2004 Sumatra-Andaman earthquake, Earth Planets Space 58, 2, 167172, DOI: $10.1186 /$ BF03353374.

Devi, M., A.J.D. Sarma, S. Kalita, A.K. Barbara, and A. Depueva (2012), Adaptive techniques for extraction of pre-seismic parameters of Total Electron Content (TEC) at anomaly crest station, Geomatics Nat. Hazards Risk 3, 3, 193206, DOI: 10.1080/19475705.2011.595831.

Dowden, R.L., C.D.D. Adams, J.B. Brundell, and P.E. Dowden (1994), Rapid onset, rapid decay (RORD), phase and amplitude perturbations of VLF subionospheric transmissions, J. Atmos. Terr. Phys. 56, 11, 1513-1527, DOI: 10.1016/0021-9169(94)90118-X.

Hayakawa, M. (1999), Atmospheric and Ionospheric Electromagnetic Phenomena Associated with Earthquakes, Terra Sci. Pub. Co., Tokyo, 996 pp.

Hayakawa, M., and Y. Fujinawa (1994), Electromagnetic Phenomena Related to Earthquake Prediction, Terra Sci. Pub. Co., Tokyo, 677 pp.

Hayakawa, M., and O.A. Molchanov (eds.) (2002), Seismo-Electromagnetics: Lithosphere-Atmosphere-Ionosphere Coupling, Terra Sci. Pub. Co., Tokyo, 477 pp.

Hayakawa, M., T. Horie, F. Muto, Y. Kasahara, K. Ohta, J.Y. Liu, and Y. Hobara (2010a), Subionospheric VLF/LF probing of ionospheric perturbations associated with earthquakes: A possibility of earthquake prediction, SICE J. Control. Meas. Syst. Integr. 3, 1, 10-14, DOI: 10.9746/jcmsi.3.10.

Hayakawa, M., Y. Kasahara, T. Nakamura, F. Muto, T. Horie, S. Maekawa, Y. Hobara, A.A. Rozhnoi, M. Solovieva, and O.A. Molchanov (2010b), A statistical study on the correlation between lower ionospheric perturbations as seen by subionospheric VLF/LF propagation and earthquakes, J. Geophys. Res. 115, A9, A09305, DOI: 10.1029/2009JA015143.

Hayakawa, M., J.P. Raulin, Y. Kasahara, F.C.P. Bertoni, Y. Hobara, and W. Guevara-Day (2011), Ionospheric perturbations in possible association with the 2010 Haiti earthquake, as based on medium-distance subionospheric VLF propagation data, Nat. Hazards Earth Syst. Sci. 11, 2, 513518, DOI: 10.5194/nhess-11-513-2011.

Hayakawa, M., Y. Hobara, A. Rozhnoi, M. Solovieva, K. Ohta, J. Izutsu, T. Nakamura, and Y. Kasahara (2013), The ionospheric precursor to the 2011 March 11 earthquake based upon observations obtained from the JapanPacific subionospheric VLF/LF network, Terr. Atmos. Ocean. Sci. 24, 3, 393-408, DOI: 10.3319/TAO.2012.12.14.01(AA).

Inan, S., T. Akgul, C. Seyis, R. Saatcilar, S. Baykut, S. Ergintav, and M. Bas (2008), Geochemical monitoring in the Marmara region (NW Turkey): A search for precursors of seismic activity, J. Geophys. Res. 113, B3, B03401, DOI: $10.1029 / 2007$ JB005206. 
Inan, U.S., V.P. Pasko, and T.F. Bell (1996), Sustained heating of the ionosphere above thunderstorms as evidenced in "early/fast" events, Geophys. Res. Lett. 23, 10, 1067-1070, DOI: 10.1029/96GL01360.

Karia, S.P., and K.N. Pathak (2011), Change in refractivity of the atmosphere and large variation in TEC associated with some earthquakes, observed from GPS receiver, Adv. Space Res. 47, 5, 867-876, DOI: 10.1016/j.asr.2010.09. 019.

Kasahara, Y., F. Muto, T. Horie, M. Yoshida, M. Hayakawa, K. Ohta, A. Rozhnoi, M. Solovieva, and O.A. Molchanov (2008), On the statistical correlation between the ionospheric perturbations as detected by subionospheric VLF/LF propagation anomalies and earthquakes, Nat. Hazards Earth Syst. Sci. 8, 4, 653-656, DOI: 10.5194/nhess-8-653-2008.

Khilyuk, L.F., G.V. Chilingar, B. Endres, and J.O. Robertson, Jr. (2000), Gas Migration: Events Preceding Earthquakes, Gulf Publishing Co., Houston, 390 pp.

Le, H., J.Y. Liu, and L. Liu (2011), A statistical analysis of ionospheric anomalies before 736 M6.0+ earthquakes during 2002-2010, J. Geophys. Res. 116, A2, A02303, DOI: 10.1029/2010JA015781.

Liu, J.Y., Y.I. Chen, Y.J. Chuo, and H.F. Tsai (2001), Variations of ionospheric total electron content during the Chi-Chi earthquake, Geophys. Res. Lett. 28, 7, 1383-1386, DOI: 10.1029/2000GL012511.

Liu, J.Y., Y.I. Chen, H.K. Jhuang, and Y.H. Lin (2004a), Ionospheric foF f $_{2}$ and TEC anomalous days associated with $\mathrm{M} \geq 5.0$ earthquakes in Taiwan during 1997-1999, Terr. Atmos. Ocean. Sci. 15, 3, 371-383.

Liu, J.Y., Y.J. Chuo, S.J. Shan, Y.B. Tsai, Y.I. Chen, S.A. Pulinets, and S.B. Yu (2004b), Pre-earthquake ionospheric anomalies registered by continuous GPS TEC measurements, Ann. Geophys. 22, 5, 1585-1593, DOI: 10.5194/ angeo-22-1585-2004.

Liu, J.Y., Y.I. Chen, Y.J. Chuo, and C.S. Chen (2006), A statistical investigation of preearthquake ionospheric anomaly, J. Geophys. Res. 111, A5, DOI: 10.1029/2005JA011333.

Liu, J.Y., Y.I. Chen, C.H. Chen, C.Y. Liu, C.Y. Chen, M. Nishihashi, J.Z. Li, Y.Q. Xia, K.I. Oyama, K. Hattori, and C.H. Lin (2009), Seismoionospheric GPS total electron content anomalies observed before the 12 May 2008 $\mathrm{M}_{\mathrm{w}} 7.9$ Wenchuan earthquake, J. Geophys. Res. 114, A4, A04320, DOI: 10.1029/2008JA013698.

Liu, J.Y., Y.I. Chen, C.H. Chen, and K. Hattori (2010), Temporal and spatial precursors in the ionospheric global positioning system (GPS) total electron content observed before the 26 December 2004 M9.3 Sumatra-Andaman earthquake, J. Geophys. Res. 115, A9, A09312, DOI: 10.1029/ 2010JA015313.

Maurya, A.K., R. Singh, B. Veenadhari, S. Kumar, and A.K. Singh (2013), Subionospheric very low frequency perturbations associated with the 12 May 
$2008 \mathrm{M}=7.9$ Wenchuan earthquake, Nat. Hazards Earth Syst. Sci. 13, 9, 2331-2336, DOI: 10.5194/nhess-13-2331-2013.

Molchanov, O.A., and M. Hayakawa (2008), Seismo-Electromagnetics and Related Phenomena: History and Latest Results, Terra Sci. Pub. Co., Tokyo, $189 \mathrm{pp}$.

Ono, Y., Y. Ida, Y. Kasahara, Y. Hobara, M. Hayakawa, A. Rozhnoi, M. Solovieva, O.A. Molchanov, and K. Ohta (2012), Ionospheric perturbations associated with two huge earthquakes in Japan, using principal component analysis for multiple subionospheric VLF/LF propagation paths, Ann. Geophys. 55, 1, 139-148, DOI: $10.4401 / \mathrm{ag}-5329$.

Peter, W.B., M.W. Chevalier, and U.S. Inan (2006), Perturbations of midlatitude subionospheric VLF signals associated with lower ionospheric disturbances during major geomagnetic storms, J. Geophys. Res. 111, A3, A03301, DOI: 10.1029/2005JA011346.

Pulinets, S. (2004), Ionospheric precursors of earthquakes; recent advances in theory and practical applications, Terr. Atmos. Ocean. Sci. 15, 3, 413-435.

Pulinets, S.A. (2009), Physical mechanism of the vertical electric field generation over active tectonic faults, Adv. Space Res. 44, 6, 767-773, DOI: 10.1016/ j.asr.2009.04.038.

Pulinets, S. (2012), Low-latitude atmosphere-ionosphere effects initiated by strong earthquakes preparation process, Int. J. Geophys. 2012, 131842, DOI: $10.1155 / 2012 / 131842$.

Pulinets, S., and K. Boyarchuk (2004), Ionospheric Precursors of Earthquakes, Springer, Berlin Heidelberg.

Pulinets, S.A., and D. Davidenko (2014), Ionospheric precursors of earthquakes and Global Electric Circuit, Adv. Space Res. 53, 5, 709-723, DOI: 10.1016/ j.asr.2013.12.035.

Pundhir, D., B. Singh, and O.P. Singh (2014), Anomalous TEC variations associated with the strong Pakistan-Iran border region earthquake of 16 April 2013 at a low latitude station Agra, India, Adv. Space Res. 53, 2, 226-232, DOI: 10.1016/j.asr.2013.11.012.

Ray, S., S.K. Chakrabarti, S.K. Mondal, and S. Sasmal (2011), Ionospheric anomaly due to seismic activities-III: correlation between night time VLF amplitude fluctuations and effective magnitudes of earthquakes in Indian subcontinent, Nat. Hazards Earth Syst. Sci. 11, 10, 2699-2704, DOI: 10.5194/ nhess-11-2699-2011.

Sarkar, S., and A.K. Gwal (2010), Satellite monitoring of anomalous effects in the ionosphere related to the great Wenchuan earthquake of May 12, 2008, Nat. Hazards 55, 2, 321-332, DOI: 10.1007/s11069-010-9530-9.

Singh, A.K., S. Kumar, R. Singh, and A.K. Singh (2012), Pre-earthquake ionospheric anomalies observed using ground based multi-instruments, Int. J. Adv. Earth Sci. 1, 1, 13-19. 
Singh, O.P., and B. Singh (2004), Ionization enhancements in sporadic E-layers prior to some major Indian earthquakes, J. Atmos. Electr. 24, 2, 75-87.

Singh, V., V. Chauhan, O.P. Singh, and B. Singh (2010), Ionospheric effect of earthquakes as determined from ground based TEC measurement and satellite data, Ind. J. Radio Space Phys. 39, 63-70.

Zhao, B., M. Wang, T. Yu, W. Wan, J. Lei, L. Liu, and B. Ning (2008), Is an unusual large enhancement of ionospheric electron density linked with the 2008 great Wenchuan earthquake? J. Geophys. Res. 113, A11, A11304, DOI: $10.1029 / 2008 J A 013613$.

Zigman, V., D. Grubor, and D. Sulic (2007), D-region electron density evaluated from VLF amplitude time delay during X-ray solar flares, J. Atmos. Sol.Terr. Phys. 69, 7, 775-792, DOI: 10.1016/j.jastp.2007.01.012.

Received 13 June 2014

Received in revised form 24 March 2015

Accepted 22 May 2015 